\title{
Análise comparativa entre as traduções de termos gastronômicos em Gabriela, Cravo e Canela e Dona Flor e seus dois maridos
}

\section{Comparative analysis between translations of gastronomy terms in Gabriela, Clove and Cinnamon and Dona Flor and her two husbands}

\author{
Ivanir A. Delvizio*
}

Laura de Almeida*

Resumo: Jorge Amado foi traduzido em vários idiomas, mas como foram estabelecidas as relações entre Língua e cultura? 0 presente trabalho visa analisar como os termos da culinária baiana foram transpostos para a Língua Inglesa. Comparamos obras do escritor em que a questão gastronômica ocupava um lugar importante. Escolhemos duas obras: Gabriela, Cravo e Canela e Dona Flor e seus dois maridos. Os termos gastronômicos foram classificados conforme a tipologia proposta por Vinay e Darbelnet. Os resultados foram analisados para verificar se existe uma padronização na tradução dos termos culturalmente marcados em obras diferentes. Além disso, verificamos o processo de distanciamento e proximidade entre as duas obras originais e suas traduções.

Palavras-chave: Língua e Cultura; tradução cultural; identidade cultural.

Professora Assistente Doutora da UNESP no curso de Turismo do Câmpus de Rosana. Desenvolve pesquisas na área de Tradução, Terminologia e Terminografia.

** Professora do Departamento de Letras e Artes na Universidade Estadual de Santa Cruz (UESC/Ilhéus/Bahia). 
DeLVIzIO, I. A.; ALMEIDA, L. DE - Análise comparativa entre as traduções de termos gastronômicos em Gabriela, Cravo e Canela e Dona Flor e seus dois maridos

Abstract: Jorge Amado was translated into many Languages, but how were relations between Language and culture established? The aim of this paper is to analyze how terms of Bahia gastronomy were translated into English Language by comparing books in which gastronomy elements play an important role. Two books were selected: Gabriela, Clove and Cinnamon, and Dona Flor and her two husbands. Terms of gastronomy were classified according to the typology proposed by Vinay and Darbelnet. Results were analyzed in order to verify ifthere is a translation standard of culturally marked terms in two different works. In addition, the process of closeness and distancing between the two original works and their translations were analyzed.

Keywords: Language and Culture; Cultural Translation; Cultural Identity.

\section{Introdução}

Não existem, tanto quanto saibamos, pesquisas específicas sobre a tradução de termos gastronômicos em obras de Jorge Amado. Dentre as pesquisas existentes sobre as traduções das obras de Jorge Amado para a Língua Inglesa, citamos Corrêa (2003), Validório e Camargo (2005), Tooge (2009), Santos e Almeida (2014).

A primeira pesquisadora realizou um estudo contrastivo de termos culturalmente marcados das obras Dona Flor e seus dois maridos, Tenda dos Milagres e Tereza Batista Cansada de Guerra, romances de Jorge Amado, e suas respectivas traduções para o Inglês, Dona Flor and her two Husbands, Tent of Miracles e Tereza Batista Home from the Wars. A autora utilizou o modelo proposto por Vinay e Darbelnet (1960) e sua reformulação por Aubert (1998), observando a prevalência das modalidades empréstimo, adaptação e explicitação. Em sua análise, Corrêa (2003: 121) faz uma menção especial aos empréstimos, classificando-os em quatro domínios: da cultura ideológica (entidades afro-brasileiras: Ojuobá, Xangô, Oxalá); da cultura material 
DeLVIZIO, I. A.; ALMEIDA, L. DE - Análise comparativa entre as traduções de termos gastronômicos em Gabriela, Cravo e Canela e Dona Flor e seus dois maridos

(afoxé, atabaque, cachaça); da cultura social (comadre, compadre, mulata) e da cultura ecológica (sertão, xaréu, pitus).

Validório e Camargo (2005) analisaram os termos culturalmente marcados nas obras O Sumiço da Santa (1988) e Mar Morto (1936), escritas por Jorge Amado, e dos respectivos textos traduzidos para o Inglês, The War of the Saints (1993) e Sea of Death (1984), por Gregory Rabassa. Porém, detiveram-se nos termos relacionados aos orixás, com pouca ênfase à culinária. Também não abordaram as obras que nos propomos a analisar aqui.

Tooge (2009), por sua vez, apresenta em sua dissertação de mestrado, intitulada Traduzindo o Brazil: o país mestiço de Jorge Amado, aspectos relativos a várias obras traduzidas de Jorge Amado para a Língua Inglesa. A autora investigou a relação entre as traduções realizadas por Alfred A. Knopf e Jorge Amado, as redes de influência e a representação cultural do Brasil na literatura traduzida de Jorge Amado nos Estados Unidos.

Mais recentemente, Santos e Almeida (2014) estudaram a temática da linguagem do candomblé e sua tradução na obra Gabriela, Cravo e Canela, observando o pouco uso de equivalentes que retratem a cultura baiana e a adoção de generalizações de termos culturalmente marcados comprometendo seu significado.

Dentre as pesquisas que abordam a temática da culinária e tradução, destacamos o estudo de Teixeira e Tagnin (2004) no qual relatam a construção de um corpus multivarietal comparável de receitas em Português brasileiro/europeu e Inglês americano/britânico. Segundo as autoras, o corpus coletado revelou que as diferenças lexicais, sintáticas e culturais entre as variantes do Português, comparadas às das variantes do Inglês, são mais expressivas, justificando traduções na variante brasileira e obras terminológicas que explicitem essas diferenças, tendo por hipótese de trabalho a verificação de que as diferenças entre o Português do Brasil e de Portugal são linguística e culturalmente mais expressivasdo que entre o Inglês americano e o britânico. 
DeLVIzIO, I. A.; ALMEIDA, L. DE - Análise comparativa entre as traduções de termos gastronômicos em Gabriela, Cravo e Canela e Dona Flor e seus dois maridos

Embora a pesquisa de Teixeira e Tagnin (2004) seja mais voltada para a Linguística de Corpus, encontramos informações pertinentes sobre a relação da culinária com a cultura de um povo, como pode ser visto no trecho seguinte: "a Culinária, além de ser um saber que permeia várias áreas do conhecimento (como a literatura, a história, a nutrição, a agricultura, a química e a física), carrega consigo marcas indeléveis da cultura de um povo, região e/ou país" (TEIXEIRA; TAGNIN 2004: 2).

Nosso trabalho, especificamente, propõe-se a comparar dois romances de Jorge Amado e suas traduções para a Língua Inglesa e verificar como os termos da culinária baiana foram traduzidos. Para isso, foram selecionadas as obras: Dona Flor e seus dois maridos (1966), doravante Dona Flor, traduzida como Dona Flor and her two husbands (1977), tradução de Harriet de Onís; e Gabriela, Cravo e Canela, doravante Gabriela, traduzida como Gabriela, Clove and Cinnamon, tradução de James L. Taylor e William L. Grossman.

Além do processo comparativo, também foi realizada uma análise acerca dos procedimentos técnicos da tradução propostos por Vinay e Darbelnet (1977) e apresentados sob a perspectiva de Barbosa (1990). Nessa proposta, os procedimentos técnicos da tradução são ordenados segundo a dificuldade de execução pelo tradutor, ou seja, quanto mais próximos da língua original, mais fácil sua realização, sendo os primeiros: o empréstimo, o decalque e a tradução literal, no âmbito da tradução direta, e os demais: a equivalência e a adaptação, no âmbito da tradução indireta ou oblíqua, que é a que mais se afasta da forma do texto da língua original.

Vale explicar também dois conceitos importantes que utilizamos em nossa análise: a amplificação, quando a mesma coisa é dita na tradução com um maior número de palavras que o do original, e a explicitação, que tem lugar toda vez que, na opinião do tradutor, o leitor da sua tradução carece de alguma informação ou esclarecimento que the proporcione um melhor entendimento do texto (CAMPOS 1987: 44). 
DeLVIZIO, I. A.; ALMEIDA, L. DE - Análise comparativa entre as traduções de termos gastronômicos em Gabriela, Cravo e Canela e Dona Flor e seus dois maridos

Fez-se preciso, também, trazer as reflexões a respeito da tradução cultural apresentadas por Aubert $(1995,1998)$. Segundo o autor, em todos os tipos de traduções enfrenta-se "o problema de traduzir a cultura", que não pode ser reduzido a uma "simples transcodificação de léxico e gramática" (AUBERT 1995: 31). Para Aubert (1995: 35-36), a tradução de elementos culturais é relativamente possível, citando três abordagens principais, não excludentes entre si: a tradução matricial, a tradução assimilativa e a tradução criativa.

Na matricial, o referencial de toda a operação concentra-se no texto e na língua/cultura do texto de partida, predominando as formas da tradução direta. Na assimilativa, inverte-se a perspectiva, com a substituição dos componentes linguístico-culturais do texto de partida por constituintes linguístico-culturais identificados com o espaço de recepção do texto traduzido, predominando os recursos da tradução oblíqua. Na criativa, que em grande parte assemelha-se à assimilativa, o tradutor assume sua coautoria, sem conformar o seu fazer a um ou outro molde externo, seja o espaço de produção ou de recepção, vencendo os temores da sacralização do original e os temores de desagradar o consumidor, imprimindo sua leitura, vivência e sensibilidade.

Ao investigar as soluções encontradas pelos tradutores para lidar com palavras e expressões ancoradas em uma cultura específica para as quais, ao menos em tese, não haveria equivalência, Aubert (1998: 122) observa que "os tradutores certamente buscam desenvolver soluções, por mais ad hoc que sejam, como opção preferível à de simplesmente eliminar as diferenças culturais".

Com base no exposto, em nossa pesquisa sobre a tradução dos termos gastronômicos nas duas obras de Jorge Amado citadas e suas respectivas traduções, buscaremos analisar, tendo como base a classificação dos procedimentos tradutórios e as reflexões feitas por Aubert $(1995,1998)$, como os tradutores lidaram com as questões culturais, verificando 0 
DelvizIO, I. A.; ALMEIDA, L. DE - Análise comparativa entre as traduções de termos gastronômicos em Gabriela, Cravo e Canela e Dona Flor e seus dois maridos

distanciamento/proximidade tradutório em relação aos termos na língua original e as tentativas de transferência de elementos culturais para a realidade linguística da língua traduzida.

\section{Análise comparativa dos termos gastronômicos e sua tradução nas duas obras de Jorge Amado}

As duas obras analisadas têm em comum a temática da gastronomia. Em Gabriela, a personagem é cozinheira de Nacib e prepara pratos diversos e típicos da cultura baiana. Da mesma forma, em Dona Flor, a protagonista é cozinheira, sendo, inclusive, professora de culinária. Inicialmente, foram levantados os termos referentes a pratos típicos da Bahia que ocorreram nas duas obras.

Como se trata de um estudo comparativo, selecionamos apenas aqueles coincidentes entre as duas obras analisadas. Uma vez selecionados os termos, verificamos como foram traduzidos nas duas obras e identificamos as modalidades tradutórias utilizadas com base no modelo de Vinay e Darbelnet (1977) e reformulado por Barbosa (1990).

Para melhor visualização e comparação das opções de tradução de cada tradutor e das modalidades utilizadas, organizamos os dados coletados no seguinte quadro ilustrativo:

Quadro 1: Análise comparativa entre Gabriela e Dona Flor em Inglês e Português.

\begin{tabular}{|c|c|c|c|c|c|}
\hline Original & Tradução & \multirow{2}{*}{$\begin{array}{l}\text { Modalidade } \\
\text { tradutória }\end{array}$} & Original & Tradução & \multirow{2}{*}{$\begin{array}{l}\text { Modalidade } \\
\text { tradutória }\end{array}$} \\
\hline $\begin{array}{l}\text { Gabriela, Cravo } \\
\text { e Canela }\end{array}$ & $\begin{array}{l}\text { Gabriela, } \\
\text { Clove and }\end{array}$ & & $\begin{array}{l}\text { Dona Flor } \\
\text { e seus }\end{array}$ & $\begin{array}{l}\text { Dona Flor } \\
\text { and her }\end{array}$ & \\
\hline
\end{tabular}


DeLVIzIO, I. A.; ALMEIDA, L. DE - Análise comparativa entre as traduções de termos gastronômicos em Gabriela, Cravo e Canela e Dona Flor e seus dois maridos

\begin{tabular}{|c|c|c|c|c|c|}
\hline & Cinnamon & & $\begin{array}{l}\text { dois } \\
\text { maridos }\end{array}$ & $\begin{array}{l}\text { two } \\
\text { husbands }\end{array}$ & \\
\hline abará & $\begin{array}{l}\text { bean paste, } \\
\text { shrimp/ bean- } \\
\text { paste balls, } \\
\text { bean-paste e } \\
\text { seasoned } \\
\text { appetizers }\end{array}$ & $\begin{array}{l}\text { Adaptação + } \\
\text { amplificação + } \\
\text { explicitação }\end{array}$ & abará & abará & Empréstimo \\
\hline acarajé & manioc meal & $\begin{array}{l}\text { Adaptação + } \\
\text { amplificação }\end{array}$ & acarajé & $\begin{array}{l}\text { bean } \\
\text { fritters }\end{array}$ & $\begin{array}{l}\text { Adaptação + } \\
\text { amplificação }\end{array}$ \\
\hline vatapá & $\begin{array}{l}\text { taro-and- } \\
\text { shrimp stew }\end{array}$ & $\begin{array}{l}\text { Adaptação + } \\
\text { amplificação }\end{array}$ & vatapá & vatapá & Empréstimo \\
\hline efó & $\begin{array}{l}\text { other local } \\
\text { dishes }\end{array}$ & generalização & efó & efó & Empréstimo \\
\hline caruru & $\begin{array}{l}\text { other local } \\
\text { dishes }\end{array}$ & generalização & caruru & caruru & Empréstimo \\
\hline
\end{tabular}

Na tradução deDona Flor,encontramos um glossário no final da obra com sessenta e seis termos. Destes, cerca de dezesseis são referentes à gastronomia, a saber: abará, acarajé, amalá, acaçá, apetê, arroz hausa, caruru, dendê, efó, feijoada, guaraná, maniçoba, moqueca, ojojó, vatapá e xinxim.

O mesmo não ocorre na tradução de Gabriela, a qual não apresenta glossário de termos regionais no final, nem notas de rodapé.

Observamos que Dona Flor apresenta um número maior de empréstimos do que em Gabriela, representados pelos termos: abará, vatapá, efó e caruru. O uso de empréstimos denota uma preocupação maior do tradutor em preservar os referentes da cultura local. Além disso, como apontamos, esses termos são explicados no glossário ao final da obra.

Por outro lado, em Gabriela, observamos que o tradutor combina vários procedimentos como a adaptação seguida de amplificação e de explicitação (abará), e de adaptação mais amplificação (acarajé e vatapá), buscando adaptar os termos à língua de chegada e explicar seu significado por meio da explicitação de ingredientes do prato. O mesmo não ocorreu com os termos 
DelvizIO, I. A.; ALMEIDA, L. DE - Análise comparativa entre as traduções de termos gastronômicos em Gabriela, Cravo e Canela e Dona Flor e seus dois maridos

efó e caruru, que foram omitidos no texto traduzido e substituídos pela expressão genérica other local dishes.

\subsection{Algumas consequências em relação às escolhas dos tradutores}

Para analisar as opções de tradução adotadas pelos tradutores e seus desdobramentos, cabe tecermos primeiramente algumas consideração acerca da relação entre a culinária baiana, cultura e religião.

A culinária baiana foi substancialmente influenciada pela culinária africana, que, por sua vez, tem uma forte ligação com a religião, especialmente o candomblé. De acordo com os estudos de Bastide (2001) sobre o candomblé, os Orixás, divindades africanas, precisam ser alimentados segundo suas preferências. Sendo assim, os fiéis fazem-lhes oferendas, em forma de pratos elaborados, chamados de comidas de santo, em um ritual que os aproxima de seus respectivos orixás.

A fim de ambientarmos os dados no contexto do candomblé, apresentamos um breve excerto em que são citadas algumas das iguarias preferidas pelas divindades africanas:

Oxalá, o grande deus, reclama os abarás, os acaçás, os bolinhos de milho brancos envolvidos em folha de bananeira, pois sua cor é o branco. Para ele é indispensável ter uma alimentação sem sal e sem pimenta, porque é o deus da bondade e da doçura. (...) Xangô reclama o amalá feito de quiabos, camarões e azeite-de-dendê. (...) lansã quer o caruru de arroz ou o angu de mandioca com acarajés (...). Enfim, o caruru dos Ibêjis, São Cosme e São Damião, é bem conhecido de todos os brasileiros. (BASTIDE 2001: 332)

Dentre as iguarias citadas acima, comentemos os termos: abará, acarajé e caruru, por terem ocorrido nas duas obras analisadas. Como 
DeLVIZIO, I. A.; ALMEIDA, L. DE - Análise comparativa entre as traduções de termos gastronômicos em Gabriela, Cravo e Canela e Dona Flor e seus dois maridos

podemos observar na citação de Bastide (2001), o termo abará está relacionado a Oxalá, e os termos caruru e acarajé estão relacionados à lansã.

Além de sua relação com a religião, cabe também explicar o significado de todos os termos analisados neste trabalho e os pratos que designam. Adiante apresentamos algumas definições consultadas no dicionário Michaelis (2009).

Abará: "sm (ioruba abará) Cul Prato comum na Bahia e no Rio de Janeiro: massa de feijão-fradinho, camarão seco e cebola; temperada com pimenta-da-costa, pijerecum ou, mesmo, malagueta, e frita às colheradas em azeite de dendê. Depois, envolvida em folha de bananeira e cozida em banhomaria." (Michaelis 2009).

Acarajé: "sm (acará1+ioruba je, comer) Folc Abará, ao qual se acrescentam camarões e muita pimenta, ficando assim mais suculento. Prato da culinária afro-brasileira." (MICHAELIS 2009).

Caruru: "2 Cul Apetitosa iguaria, preparada com carne de galinha, peixe, quiabos, azeite de dendê e pimenta." (MICHAELIS 2009).

Efó: "prato da culinária baiana preparado com folhas de língua-devaca, camarões secos moídos, temperos, cabeça de peixe e azeite de dendê" (Michaelis, 2009).

Vatapá: "sm Cul Prato da cozinha afro baiana, feito de peixe ou crustáceos numa papa de farinha de mandioca, temperado com azeite de dendê, e às vezes, pimenta." (MichaELIS 2009).

Em relação à tradução desses termos e à escolha dos tradutores, observamos que, em Gabriela, houve a predominância das adaptações para expressar o termo cultural.

Em Gabriela, as traduções para "abará" e "acarajé” foram, respectivamente, em Inglês, para o primeiro termo: bean paste, shrimp/ bean-paste balls, bean-paste e seasoned appetizers, significando respectivamente: pasta de feijão, camarão/ bolinhos de pasta de feijão, 
DeLVIzIO, I. A.; ALMEIDA, L. DE - Análise comparativa entre as traduções de termos gastronômicos em Gabriela, Cravo e Canela e Dona Flor e seus dois maridos

pasta de feijão e tipo de aperitivo. Para o segundo: manioc meal (refeição de mandioca), realizadas por meio dos procedimentos de amplificação, explicitação e adaptação, recorrendo-se a um maior número de palavras que o do original para explicitar o significado do termo e à substituição de elementos linguístico-culturais do texto de partida por elementos inseridos no espaço de recepção do texto traduzido.

Continuando em Gabriela, os pratos "vatapá, caruru, efó" foram traduzidos como taro-and-shrimp stew and other local dishes. 0 termo vatapá, especificamente, também por um processo de adaptação e amplificação, foi traduzido como taro-and-shrimp stew (ensopado de inhame e camarão). Já os termos caruru e efó foram traduzidos genericamente pela expressão other local dishes (outros pratos locais).

Nesses casos, o leitor estrangeiro é privado do contato com os termos efetivamente usados para nomear os pratos, sendo, por vezes, remetido a elementos de sua própria cultura, não dispondo de nenhuma nota ou glossário que traga informações adicionais sobre os elementos culturais e religiosos atrelados a esses pratos.

Em Gabriela, a não tradução dos termos "caruru" e "efó", que aparecem como other local dishes, configura-se como uma generalização, não havendo nenhum tipo de informação que possibilite ao leitor saber que esse tipo de comida é dedicado a santos, no caso São Cosme e Damião, na religião católica, e Ibeji ou Ibêje, no candomblé, como podemos observar em Póvoas:

Caruru. m. Cerimônia do candomblé em que se festejam os gêmeos Ibeji, sincretizados no Brasil com os santos católicos Cosme e Damião. (...) Repasto comunal oferecido às crianças em homenagem aos Erê (v.), constituído das mais diversas iguarias próprias do candomblé. (PóvoAs 1989: 162)

Quanto ao "caruru", citamos o trecho abaixo que ilustra o seu significado na cultura baiana: 
DeLVIzIO, I. A.; ALMEIDA, L. DE - Análise comparativa entre as traduções de termos gastronômicos em Gabriela, Cravo e Canela e Dona Flor e seus dois maridos

$\mathrm{Na}$ tarde de 25 de setembro tem lugar o caruru dos pequenos. 0 número de crianças participantes, pertencentes à família ou convidadas, não pode ser inferior a sete, que é o algarismo dos Gêmeos. (...) os quiabos são esmagados, mas sete devem permanecer inteiros; aquele que os encontrar deverá oferecer, no ano seguinte, a festa dos Santos Gêmeos àqueles que no ano precedente os convidaram. Certos candomblés da Bahia festejam também os Gêmeos com o nome africano de Ibêjis, mas no decorrer de uma cerimônia que não lhes é especialmente consagrada, e sim aos erês. (...) (BASTIDE 2001: 195/196)

Para Póvoas (1989: 105), em relação ao Caruru de Cosme-Damião, é próprio do candomblé oferecer iguarias aos Erê, reminiscência do culto ao Ibeji, os gêmeos africanos que se identificaram no Brasil com os santos católicos, São Cosme e São Damião.

Campos (1987) ressalta que o procedimento da adaptação corresponde ao limite extremo da tradução: aplica-se em casos nos quais a situação toda a que se refere o texto da língua original (TLO) não existe na realidade extralinguística dos falantes da Língua traduzida (LT). Essa situação pode ser recriada por outro equivalente na realidade extralinguística da LT (BARBOSA 1990: 76).

Em relação à obra Dona Flor, observamos que foi predominante o uso dos empréstimos, aproximando-se mais do texto de origem. No texto traduzido para o inglês, foram adotados os empréstimos abará, vatapá, caruru e efó, com exceção do termo acarajé, que, por um processo de amplificação e adaptação, foi traduzido como bean fritters (fritada de feijão), com todos os desdobramentos já comentados nos casos anteriores.

O uso dos empréstimos, a seu turno, aproxima o leitor do texto original e dá um toque de estrangeiridade ao texto, dando-lhe cor local. Nesse caso, o leitor tem um contato direto com o termo utilizado para nomear o prato. Por outro lado, pode-se argumentar que o empréstimo, por si só, não traz elementos que permitam ao leitor compreender do que se trata esses pratos, 
DeLVIzIO, I. A.; ALMEIDA, L. DE - Análise comparativa entre as traduções de termos gastronômicos em Gabriela, Cravo e Canela e Dona Flor e seus dois maridos

como acontece no caso do uso dos procedimentos da amplificação e explicitação, por exemplo. Essa deficiência, entretanto, foi suprida pela tradutora por meio da disponibilização de um glossário, que traz informações sobre os pratos e suas inter-relações com cultura e religião.

\section{Considerações finais}

Buscamos abordar e discutir uma análise comparativa entre duas obras de Jorge Amado traduzidas para a Língua Inglesa no que se refere à tradução de termos relativos à culinária baiana.

Observamos que em Gabriela existe menos preocupação em traduzir as diferenças entre a cultura original brasileira e as culturas da Língua Inglesa. Já em Dona Flor, nota-se que a tradutora procurou mecanismos para exemplificar as duas culturas em questão. Em Gabriela não constatamos a preocupação em retratar os termos culturalmente marcados, como pudemos constatar no uso das adaptações e generalizações nos casos de "acarajé', "caruru" e "vatapá". Enquanto que em Dona Flor, algumas constatações foram destacadas: a tradutora demonstra ter não só conhecimento linguístico, como também cultural; constatou-se que o procedimento mais utilizado foi o empréstimo; a tradutora demonstra respeito pela identidade baiana, revelando uma tradução preocupada com o enriquecimento intercultural.

Verificamos, assim, que o enredo das obras em si é passado para o leitor da Língua Inglesa, porém, os elementos relacionados ao candomblé são muitas vezes "apagados" na tradução. Não presenciamos a inclusão da cultura africana em todo o percurso, mas será isso intencional? Acreditamos que as escolhas do tradutor interferem e muito na compreensão de mundo que o leitor fará ao ler a obra traduzida, a conhecer a cultura local. Estudos futuros 
DeLVIZIO, I. A.; ALMEIDA, L. DE - Análise comparativa entre as traduções de termos gastronômicos em Gabriela, Cravo e Canela e Dona Flor e seus dois maridos

podem abranger outras obras traduzidas e verificar outros aspectos culturais pertinentes.

\section{Referências bibliográficas}

AMADO, J. Dona Flor and her two husbands. Tradução norte-americana de Harriet De Onís, H. New York: Alfred A. Knopf, 2006. .Dona Flor e seus dois maridos. São Paulo: Martins, 1966. .Gabriela, Cravo e Canela. São Paulo: Martins, 1958. . Gabriela, Clove and Cinnamon. Nova York: Alfred A. Knopf.Tradução norte-americana de James L. Taylor e William L. Grossman, 1962.

AUBerT, F. H. Desafios da tradução cultural. TradTerm, n. 2. São Paulo, FFLCH/ CITRAT, pp. 31-44, 1995.

- Modalidades de tradução: teoria e resultados. TradTerm, 5 (1), $1^{\circ}$ semestre, pp. 99-128. São Paulo, CITRAT -- FFLCH/USP, 1998.

Barbosa, H. G. Procedimentos técnicos da tradução: uma nova proposta. Campinas: Pontes, 1990.

BASTIDE, R. O candomblé da Bahia: rito nagô. Tradução Maria Isaura Pereira de Queiroz; revisão técnica Reginaldo Prandi. Título original: Le candomblé de Bahia (rite nagô). São Paulo: Companhia das Letras, 2001.

CAMPOS, G. O que é tradução. 2. ed. São Paulo: Brasiliense, 1987.

CORRÊA, R. H. M. A. A tradução dos marcadores culturais extra-lingüísticos: Jorge Amado Traduzido. Tradterm, São Paulo, v. 9, pp. 93-137, 2003.

MiCHAelIS. Michaelis Moderno Dicionário da Língua Portuguesa. São Paulo: Melhoramentos, 2009. Disponível em: http://michaelis.uol.com.br. Acesso em 29 dez. 2015.

PóvOAS, R. C. A linguagem do candomblé: níveis sociolingüísticos de integração afro-portuguesa. Rio de Janeiro: José Olympio, 1989. 
DeLVIZIO, I. A.; ALMEIDA, L. DE - Análise comparativa entre as traduções de termos gastronômicos em Gabriela, Cravo e Canela e Dona Flor e seus dois maridos

SANTOS, R. C. F.; AlmeidA, L. de. A versão cultural de orixás na tradução do romance Gabriela, Cravo e Canela. In: Seminário de pesquisa e extensão em letras, n. 5, Ithéus, 2013. Anais...lthéus: UESC, 2013. Disponível em: www.uesc.br/eventos/sepexle/vsepexle/anais_v_tomocompleto.pdf. Acesso em: 13 novembro 2014.

TeiXeIRA, E. D., TAGnin, S. E. O. Lingüística de corpus e tradução Técnica: relato da montagem de um Corpus multivarietal de culinária. TradTerm, v. 10, pp. 313-358, 2004.

Tooge, M. D’A. B. Traduzindo o Brazil: o país mestiço de Jorge Amado. $267 \mathrm{f}$. Dissertação (Mestrado) - Faculdade de Filosofia, Letras e Ciências Humanas, Universidade de São Paulo, São Paulo, 2009.

ValidóRIO, V. C.; CamaRgo, D. C. Um estudo da tradução de termos culturalmente marcados em $O$ Sumiço da Santa: The War of The Saints e Mar Morto: Sea of Death, de Jorge Amado, Traduzidas por Gregory Rabassa. Estudos linguísticos XXXIV. 2005, pp. 1349-1354. Disponível em: http://www.gel.org.br/estudoslinguisticos/edicoesanteriores/4publicaestudos-2005/4publica-estudos-2005-pdfs/analise-de-termos-culturamente1737.pdf. Acesso em: 1 set. 2014.

VINAY, J. P; DaRbelnet, J. Stylistique comparée du français et de l'anglais: méthode de traduction. Paris: Didier, 1958; edição revista e corrigida, 1977. 